\title{
PENGGUNAAN LIDAH BUAYA (Aloe vera) SEBAGAI KOAGULAN ALAMI UNTUK MENURUNKAN KEKERUHAN AIR
}

Elly January ${ }^{1}$, Heri Shatriadi Chandra Putra ${ }^{2}$, Zairinayati ${ }^{3 *}$

1,2,3 STIKes Muhammadiyah Palembang

\section{Artikel Info :}

Received 28 Juli 2020

Accepted 14 April 2021

Available online 30 April 2021

Editor: Imam Santosa

Keyword :

Aloe vera, clean-water, coagulant, turbidity

Kata kunci :

Aloe vera, air bersih, koagulan, kekeruhan

Ruwa Jurai: Jurnal Kesehatan Lingkungan is licensed under a Creative Commons Attribution-NonCommercial 4.0 International License.

\begin{abstract}
A bstract
Dug wells are the most widely used clean water facilities in the community, but they often have high turbidity levels. So that processing must be done using a coagulant material. Aloe vera is a natural ingredient that contains complex carbohydrates, sugars, and mucilages which can bind particles in water. This study aims to determine the effect of variations in Aloe vera doses on reducing water turbidity. This study used a completely randomized design (CRD) with three dose variations $(0.1 \mathrm{ml}, 0.2 \mathrm{ml}$, and $0.3 \mathrm{ml})$ and six repetitions. A total of $500 \mathrm{ml}$ of raw water from resident wells was used for each treatment. The results showed that at a dose of $0.1 \mathrm{ml}$, the turbidity decreased by $3.7 \%$, from 41.1 NTU to 39.6 NTU (SD = 0.54). The dose was $0.2 \mathrm{ml}$, decreased by $6.8 \%$ (38.3 NTU; SD = 1.54), and the dose was $0.3 \mathrm{ml}$ decreased by $13.9 \%$ (35.4 NTU; $S D=1.02)$. Statistically, it showed a significant difference in turbidity in each treatment group ( $p$-value $<0.05$ ). Research has shown that Aloe vera can be used as a natural coagulant, but further research is needed to determine the correct dosage.

Sumur gali merupakan sarana air bersih yang paling banyak digunakan masyarakat. Namun seringkali memiliki tingkat kekeruhan yang tinggi, sehingga harus dilakukan pengolahan menggunakan bahan koagulan. Lidah buaya (Aloe vera) adalah bahan alami yang memiliki kandungan karbohidrat kompleks, gula, dan mucilage yang dapat mengikat partakel dalam air. Penelitian bertujuan mengetahui pengaruh variasi dosis Aloe vera terhadap penurunan kekeruhan air. Penelitian menggunakan rancangan acak lengkap (RAL) dengan tiga variasi dosis $(0,1 \mathrm{ml}, 0,2 \mathrm{ml}$, dan 0,3 ml) dan enam pengulangan. Sebanyak $500 \mathrm{ml}$ air baku dari sumur penduduk digunakan pada setiap perlakuan. Hasil penelitian mendapatkan, pada dosis $0,1 \mathrm{ml}$ terjadi penurunan kekeruhan sebesar 3,7\%, dari 41,1 NTU menjadi 39,6 NTU $(S D=0,54)$. Dosis $0,2 \mathrm{ml}$, penurunan $6,8 \%$ (38,3 NTU; $S D=1,54)$, dan dosis $0,3 \mathrm{ml}$ penurunan $13,9 \%$ (35,4 NTU; $S D=1,02$ ). Secara statistik, menunjukkan perbedaan kekeruhan yang signifikan pada setiap kelompok perlakuan ( $p$-value < 0,05). Penelitian membuktikan bahwa Aloe vera dapat digunakan sebagai koagulan alami, namun perlu penelitian lebih lanjut untuk menentukan dosis yang tepat.
\end{abstract}

*Corresponding author: Zairinayati

Prodi DIII Kesehatan Kesehatan Lingkungan STIKes Muhammadiyah Palembang, Sumatera Selatan

Jl. Jenderal Ahmad Yani, 13 Ulu, Kec. Seberang Ulu II, Kota Palembang, Sumatera Selatan 30262. Indonesia.

Email: ellymisnan98@gmail.com

\section{PENDAHULUAN}

Dalam kehidupan sehari-hari, air dipergunakan untuk keperluan higiene sanitasi, minum, memasak dan pelarut obat. Kualitas air untuk keperluan higiene sanitasi berbeda dengan kualitas air minum (Kementerian Kesehatan RI, 2017). Bermacam-macam sumber air yang dapat dimanfaatkan sebagai sumber air bersih, yaitu air hujan, air sungai, air laut, air danau dan air sumur. Sumur gali merupakan sarana air bersih yang paling banyak digunakan masyarakat, bersumber dari air tanah dengan kedalaman 710 meter (Gabriel. J. F, 2001).

Permasalahan yang sering terjadi dalam penyediaan air bersih ialah pencemaran. Pencemaran terjadi akibat masuknya atau dimasukkannya makhluk hidup, zat, energi dan 
atau komponen lain ke dalam air dari kegiatan manusia, sehingga kualitas air turun sampai ke tingkat tertentu yang menyebabkan air tidak dapat berfungsi sesuai dengan peruntukannya. Salah satu tanda air telah tercemar adalah kekeruhan, karena mengandung banyak partikel tersuspensi. Partikel tersuspensi memberikan perubahan warna/rupa pada fisik air. Bahanbahan yang menyebabkan kekeruhan antara lain, tanah liat, lumpur, bahan organik dan partikel tersuspensi (Rifa'i J., 2007).

Kabupaten Banyuasin adalah salah satu kabupaten di Provinsi Sumatera Selatan, sebagai penyangga ibukota provinsi. Kelurahan Tanah Mas, Kecamatan Talang Kelapa merupakan salah satu wilayah di Kabupaten Banyuasin yang memiliki permasalahan kekeruhan air. Berdasarkan hasil studi pendahuluan, kualitas fisik air sumur keruh, dan meningkat pada sat musim hujan. Hasil pengukuran sebesar 41,09 NTU, di atas batas maksimum yang diperbolehkan (Kementerian Kesehatan RI, 2017).

Proses penjernihan air memerlukan koagulan, yaitu bahan kimia yang dicampurkan ke dalam air baku sehingga terjadi aglomerasi partikel koloid dan terbentuk flock (Idris et al., 2013). Pemilihan bahan alami sebagai koagulan untuk mengurangi penggunaan bahan sintetik yang memberikan dampak terhadap kesehatan (Furnawanthi, 2002). Penelitian sebelumnya membuktikan bahwa lidah buaya (Aloe vera) dapat digunakan sebagai koagulan alami. Pada konsentrasi $0,1 \mathrm{ml}$ dapat menurunkan kekeruhan hingga 62,21\% (Mujariah et al., 2016).

Aloe vera merupakan tanaman yang termasuk golongan Liliaceae (Pichler et al., 2012). Biasanya, Aloe vera digunakan sebagai penyubur rambut, penyembuh luka, perawatan kulit, serta bahan makanan dan minuman kesehatan. Kemampuan Aloe vera sebagai koagulan karena mengandung karbohidrat kompleks dan gula yang dapat mengikat partikel-partikel di dalam air (Maharani et al., 2020; Musriyah, 2016), juga mengandung mucilage atau gel seperti pada tumbuhan kaktus yang dapat digunakan sebagai penjernih air (Mujariah et al., 2016; Permatasari, 2013; Pichler et al., 2012; Pranata et al., 2019; Puspitasari et al., 2013).

Di wilayah Kelurahan Tanah Mas, tanaman Aloe vera banyak ditanam di halaman rumah sebagai tanaman hias. Penelitian bertujuan mengetahui kemampuan Aloe vera sebagai koagulan alami. Pengamatan penurunan kekeruhan dilakukan pada beberapa dosis bahan, serta efek perlakuan terhadap $\mathrm{pH}$ dan suhu air olahan.

\section{BAHAN dan METODE}

Eksperimen menggunakan rancangan acak lengkap (RAL), untuk mengetahui pengaruh dosis Aloe vera terhadap penurunan kekeruhan air. Penelitian dilaksanakan pada bulan Mei 2019 di laboratorium STIKes Muhammadiyah Palembang, dan sampel diambil dari sumur gali milik masyarakat di Kelurahan Tanah Mas, Kecamatan Talang Kelapa, Kabupaten Banyuasin. Variasi dosis perlakuan adalah $0,1 \mathrm{ml}, 0,2 \mathrm{ml}$, dan $0,3 \mathrm{ml}$ gel Aloe vera, dan dibandingkan dengan kontrol. Penentuan dosis perlakuan mengikuti (Mujariah et al., 2016), pada dosis 0,1 ml, mampu menurunkan kekeruhan sebesar 62,21\%. Pengulangan dilakukan sebanyak enam kali, mengikuti pada formula Federer.

\section{Pembuatan masarasi Lidah buaya}

Daun lidah buaya yang digunakan adalah daun lidah buaya tua (bagian pangkal). Daun lidah buaya segar disimpan pada suhu ruang selama 2-3 hari, kemudian dicuci dengan air mengalir untuk menghilangkan kotoran-kotoran yang menempel. Selanjutnya kulit daun lidah dikupas, dipotong menjadi bagian yang lebih kecil, selanjutnya dihaluskan menggunakan blender. Bubur daun lidah buaya disaring sehingga diperoleh masarasi lidah buaya. Masarasi lidah buaya disimpan dalam wadah yang bersih dan kering untuk digunakan sebagai bahan koagulan.

\section{Proses pengolahan air}

Sebanyak $500 \mathrm{ml}$ sampel (air sumur) dimasukkan ke dalam gelas beker. Pemberian bahan koagulan dilakukan pada beberapa dosis $(0,1 \mathrm{ml}, 0,2 \mathrm{ml}$, dan $0,3 \mathrm{ml})$, dan dilakukan pengadukan cepat (100 rpm) menggunakan Magnetic Stirrer selama 20 menit, dan didiamkan selama 30 menit. Perlakuan diulangi sebanyak enam kali. Pengukuran kekeruhan dilakukan pada setiap perlakuan menggunakan Turbidymeter, dan dibandingkan dengan kontrol. 
Keasaman air $(\mathrm{pH})$ dan suhu air hasil olahan diukur untuk mengetahui efek perlakuan. Seluruh data dianalisis dengan uji ANOVA.

\section{HASIL}

Pada Tabel 1 terlihat, hasil pengukuran kekeruhan pada air baku (kontrol) sebesar 41,1 NTU. Perlakuan menggunakan dosis Aloe vera
$0,1 \mathrm{ml}$, rata-rata angka kekeruhan menjadi 39,6 NTU $(S D=0,54)$, atau penurunan 3,7\%. Pada dosis $0,2 \mathrm{ml}$, menjadi $38,3 \mathrm{NTU}(\mathrm{SD}=1,54)$ atau penurunan $6,8 \%$. Pada dosis $0,3 \mathrm{ml}$, menjadi 35,4 NTU $(1 \mathrm{SD}=1,02)$, menunjukkan penurunan terbesar, yaitu $13,9 \%$.

Tabel 1. Hasil pengukuran kekeruhan

\begin{tabular}{|c|c|c|c|c|c|c|c|c|}
\hline \multirow{2}{*}{ Variabel } & \multicolumn{6}{|c|}{ Kekeruhan (NTU) } & \multirow{2}{*}{$\begin{array}{l}\text { Rata-rata } \\
\text { (SD) }\end{array}$} & \multirow{2}{*}{$\begin{array}{l}\text { Penurun } \\
\text { an }\end{array}$} \\
\hline & 1 & 2 & 3 & 4 & 5 & 6 & & \\
\hline Kontrol & 41,1 & 41,1 & 41,1 & 41,1 & 41,1 & 41,1 & 41,1 & - \\
\hline Dosis $0,1 \mathrm{ml}$ & 40,3 & 40,1 & 39,0 & 39,1 & 39,3 & 39,6 & $39,6(0,54)$ & $3,7 \%$ \\
\hline Dosis $0,2 \mathrm{ml}$ & 39,7 & 38,7 & 39,4 & 39,2 & 36,2 & 36,5 & $38,3(1,54)$ & $6,8 \%$ \\
\hline Dosis $0,3 \mathrm{ml}$ & 34,7 & 36,5 & 36,2 & 34,2 & 36,2 & 34,5 & $35,4(1,02)$ & $13,9 \%$ \\
\hline
\end{tabular}

Efek suhu pada perlakuan diukur dengan Thermometer (Tabel 2). Hasil pengukuran ratarata suhu air baku sebelum perlakuan (kontrol) sebesar $29^{\circ} \mathrm{C}$. Pada perlakuan menggunakan dosis Aloe vera $0,1 \mathrm{ml}$, suhu meningkat menjadi
29,8 (SD=0,41). Pada dosis $0,2 \mathrm{ml}$, meningkat menjadi 29,8 ( $S D=1,33)$. Sedangkan pada dosis $0,3 \mathrm{ml}$, terjadi peningkatan suhu tertinggi menjadi 30,3 (SD=0,52).

Tabel 2. Hasil pengukuran suhu dan $\mathrm{pH}$

\begin{tabular}{lllllllllllllll}
\hline \multirow{2}{*}{ Variabel } & \multicolumn{1}{c}{ Suhu $\left({ }^{\circ} \mathrm{C}\right)$} & \multicolumn{11}{c}{$\mathrm{pH}$} \\
\cline { 2 - 13 } & 1 & 2 & 3 & 4 & 5 & 6 & Mean & 1 & 2 & 3 & 4 & 5 & 6 & Mean \\
\hline Kontrol & 29 & 29 & 29 & 29 & 29 & 29 & 29,0 & 7,1 & 7,1 & 7,1 & 7,1 & 7,1 & 7,1 & 7,1 \\
Dosis 0,1 ml & 30 & 29 & 30 & 30 & 30 & 30 & 29,8 & 7,5 & 7,4 & 7,3 & 7,5 & 7,5 & 7,2 & 7,4 \\
Dosis 0,2 ml & 28 & 30 & 29 & 30 & 30 & 32 & 29,8 & 7,5 & 7,4 & 7,3 & 7,2 & 7,3 & 7,3 & 7,3 \\
Dosis 0,3 ml & 30 & 30 & 31 & 30 & 31 & 30 & 30,3 & 7,5 & 7,2 & 7,5 & 7,4 & 7,5 & 7,5 & 7,4 \\
\hline
\end{tabular}

Tabel 2 menunjukkan nilai rata-rata $\mathrm{pH}$ pada air baku (kontrol) sebesar 7,1. Setelah perlakuan menggunakan Aloe vera dosis $0,1 \mathrm{ml}, \mathrm{pH}$ meningkat menjadi $7,4(S D=0,13)$. Pada dosis 0,2 $\mathrm{ml}, \mathrm{pH}$ naik menjadi $7,3(\mathrm{SD}=0,10)$. Pada dosis $0,3 \mathrm{ml}, \mathrm{pH}$ meningkat menjadi $7,4(\mathrm{SD}=0,12)$.

Analisis statistik dilakukan menggunakan uji ANOVA (alpha $=0,05)$ untuk mengetahui perbedaan kekeruhan berdasarkan dosis Aloe vera yang digunakan (Tabel 3). Hasil analisis menunjukkan perbedaan rata-rata kekeruhan yang signifikan antar kelompok yang diamati $(p<0,01)$. Disimpulkan, ada pengaruh pemberian dosis Aloe vera terhadap perubahan nilai kekeruhan air baku.

Uji Benferroni digunakan untuk mengetahui perbedaan antar kelompok pengamatan. Pada Tabel 4 terlihat bahwa nilai kekeruhan air baku berbeda secara signifikan dengan setelah perlakuan dengan dosis Aloe vera $0,2 \mathrm{ml}$ dan 0,3 $\mathrm{ml}$. Pada dosis $0,3 \mathrm{ml}$, nilai kekeruhan air olahan secara signifikan berbeda dengan kontrol dan kelompok perlakuan lainnya. Dosis 0,3 ml memberikan pengaruh terbesar terhadap penurunan kekeruhan air baku.

Tabel 3. Hasil uji ANOVA

\begin{tabular}{llllll}
\hline & Sum of Squares & $\mathrm{df}$ & Mean Square & $\mathrm{F}$ & Sig. \\
\hline Between Groups & 105,78 & 3 & 35,26 & 38,22 & 0,0001 \\
Within Groups & 18,45 & 20 & 0,92 & & \\
Total & 124,23 & 23 & & & \\
\hline
\end{tabular}


Tabel 4. Hasil uji Benferroni

\begin{tabular}{lllll}
\hline \multirow{2}{*}{ Variabel } & p-value & & & \\
\cline { 2 - 5 } & Kontrol & $0,1 \mathrm{ML}$ & $0,2 \mathrm{ML}$ & $0,3 \mathrm{ML}$ \\
\hline Kontrol & - & 0,072 & 0,000 & 0,000 \\
Dosis $0,1 \mathrm{ml}$ & 0,072 & - & 0,188 & 0,000 \\
Dosis $0,2 \mathrm{ml}$ & 0,000 & 0,188 & - & 0,000 \\
Dosis $0,3 \mathrm{ml}$ & 0,000 & 0,000 & 0,000 & - \\
\hline
\end{tabular}

\section{PEMBAHASAN}

Berdasarkan Tabel 1, penurunan kekeruhan terbesar terjadi pada konsentrasi $0,3 \mathrm{ml}(35,4$ NTU), sedangkan penurunan terkecil pada dosis 0,1 ml (39,6 NTU). Hasil uji ANOVA mendapatkan nilai $p$-value $<0,01$, menunjukkan adanya perbedaan nilai rata-rata kekeruhan sebelum dan sesudah perlakuan. Perbedaan signifikan terlihat pada konsentrasi $0,2 \mathrm{ml}$ dan $0,3 \mathrm{ml}$. Penambahan konsentrasi koagulan yang tepat akan membantu proses koagulasi melalui charge neutralization dan interparticle bridging. Jika konsentrasi koagulan tidak mencukupi atau berlebih, akan mengakibatkan buruknya kinerja dalam proses koagulasi (Vijayaraghavan and Shanthakumar, 2015).

Hasil penelitian ini mengonfirmasi penelitian (Mujariah et al., 2016) yang menyatakan bahwa Aloe vera dapat digunakan sebagai koagulan alami. Aloe vera termasuk dalam golongan Liliaceae (Pichler et al., 2012). Biasanya, Aloe vera digunakan sebagai penyubur rambut, penyembuh luka, perawatan kulit, serta bahan makanan dan minuman kesehatan. Aloe vera dapat digunakan sebagai koagulan karena mengandung karbohidrat kompleks dan gula yang dapat mengikat partikel-partikel di dalam air (Maharani et al., 2020; Musriyah, 2016). Aloe vera juga mengandung mucilage seperti pada tumbuhan kaktus yang telah digunakan sebagai penjernih air (Mujariah et al., 2016; Permatasari, 2013; Pranata et al., 2019; Puspitasari et al., 2013).

Pada proses koagulasi, bahan koagulan yang dicampurkan ke dalam air baku menyebabkan terjadinya destabilisasi koloid. Koloid yang sudah kehilangan muatannya atau terdestabilisasi, akan saling tarik menarik sehingga membentuk gumpalan (flock) yang lebih besar dan akhirnya mengendap akibat peningkatan massa (Furnawanthi, 2002). Proses filtrasi merupakan proses lanjutan untuk menyaring flock hasil koagulasi (Yawaritsa et al., 2019).

Air untuk keperluan higiene sanitasi harus memenuhi persyaratan kesehatan yang meliputi parameter fisik, biologi, dan kimia. Persyaratan kekeruhan air untuk keperluan higiene sanitasi, termasuk yang digunakan untuk air minum, adalah sebesar 25 NTU (Kementerian Kesehatan $\mathrm{RI}$, 2017). Pada penelitian ini, penurunan kekeruhan tertinggi pada penggunaan dosis Aloe vera $0,3 \mathrm{ml}$, dari $41,1 \mathrm{NTU}$ menjadi 35,4 NTU, terjadi penurunan sebesar 13,9\%. Nilai kekeruhan belum memenuhi persyaratan kesehatan, sehingga perlu penelitian lebih lanjut untuk mendapatkan dosis tepat dalam pengolahan air.

Hasil penelitian juga mendapatkan bahwa setelah pemberian Aloe vera, tidak terjadi perubahan suhu dan $\mathrm{pH}$ air secara nyata. Peningkatan suhu hanya sebesar $0,8-1,3^{\circ} \mathrm{C}$, sedangkan peningkatan $\mathrm{pH}$ sebesar 0,3-0,9. Hasil ini mengindikasikan proses kimia terjadi secara lambat. Peningkatan suhu pada air akan mempercepat reaksi-reaksi kimia (Taufiqullah, 2020). Berdasarkan Peraturan Menteri Kesehatan Republik Indonesia Nomor 32 Tahun 2017, suhu dan $\mathrm{pH}$ air olahan masih memenuhi persyaratan yang ditetapkan, yaitu suhu $\pm 3^{\circ} \mathrm{C}$ dari suhu udara, dan pH 6,8 - 8,5 (Kementerian Kesehatan $\mathrm{RI}, 2017)$.

\section{SIMPULAN}

Penggunaan Aloe vera dengan dosis $3 \mathrm{ml}$ pada $500 \mathrm{ml}$ air baku, dapat menurunkan kekeruhan dari 41,1 NTU menjadi 35,4 NTU $(S D=1,02)$, atau penurunan sebesar $13,9 \%$. Perubahan suhu dan $\mathrm{pH}$ secara signifikan tidak terjadi pada percobaan. Penelitian membuktikan 
bahwa Aloe vera dapat digunakan sebagai koagulan alami dalam proses penjernihan air.

\section{DAFTAR PUSTAKA}

Furnawanthi, I., 2002. Khasiat dan manfaat lidah buaya. AgroMedia Pustaka, Jakarta.

Gabriel. J. F, 2001. Fisika Lingkungan. Penerbit Hipokrates, Jakarta.

Idris, J., Som, A.M., Musa, M., Hamid, K.H.K., 2013. Dragon fruit foliage plant-based coagulant for treatment of concentrated latex effluent: Comparison of treatment with ferric sulfate. Journal of Chemistry 1-7.

Kementerian Kesehatan RI, 2017. Peraturan Menteri Kesehatan Republik Indonesia nomor 32 tahun 2017 tentang Standar Baku Mutu Kesehatan Lingkungan Dan Persyaratan Kesehatan Air Untuk Keperluan Higiene Sanitasi, Kolam Renang, Solus Per Aqua, Dan Pemandian Umum.

Maharani, A., Prambudi, A.R., Udyani, K., 2020. Pengolahan air sumur di daerah Simolawang menggunakan metode koagulasi dengan koagulan Aloe vera. Seminar Nasional Sains dan Teknologi Terapan 1, 315-322.

Mujariah, Abram, P. hengki, Jura, M.R., 2016. The Use of Aloe Vera Gel ( Aloe Vera) As A Natural Coagulant in Well Water Purification at The Sausu Tambu Village District Sa. Jurnal Akad. Kim 5, 16-22.

Musriyah, 2016. Manfaat Air Bagi Manusia, Hewan dan Tanaman [WWW Document]. Dipetik 18
April 2017, dari Website Resmi Pemerintah:

Permatasari, T.J., 2013. Optimasi Penggunaan

Koagulasi Dalam Proses Penjernihan Air. jurnal Sains dan Seni 2, A-7.

Pichler, T., Young, K., Alcantar, N., 2012. Eliminating turbidity in drinking water using the mucilage of a common cactus. Water Science \& Technology: Water Supply. 179-186.

Pranata, M.F., A., S., Raharja, M., 2019. Perbaikan Kualitas Air Menggunakan Gel Lidah buaya (Aloe vera). Jurnal Kesehatan Lingkungan 16, 763-790.

Puspitasari, D., Setiawan, A., Dewi, T.U., 2013. Penggunaan Lidah Buaya sebagai Biokoagulan di Industri Minyak 141-144.

Rifa'i J., 2007. Pemeriksaan kualitas air bersih dengan koagulan alum dan PAC di Ipa Jurug PDAM Kota Surakarta.

Taufiqullah, T., 2020. Pengaruh Suhu Terhadap Kualitas Air [WWW Document]. TNeutron.

Vijayaraghavan, G., Shanthakumar, S., 2015. Efficacy of Moringa oleifera and Phaseolus vulgaris (common bean) as coagulants for the removal of Congo red dye from aqueous solution. Journal of Materials and Environmental Science 6, 1672-1677.

Yawaritsa, Y., Daud, S., Asmura, J., 2019. Penyisihan Warna dan Zat Organik (KMnO4) pada Air Gambut dengan Biokoagulan Gel Lidah Buaya. JOM FTEKNIK 6, 1-8. 